\title{
Validação e Adaptação Transcultural da Escala Multidimensional de Atitudes Face a Lésbicas e a Gays
}

\author{
Validation and Transcultural Adaptation of the Multidimensional Scale \\ of Attitudes toward Lesbians and Gay Men
}

\author{
Jorge Gato*, ${ }^{*}$, Anne Marie Fontaine ${ }^{a} \&$ Vanessa B. R. Leme ${ }^{b}$ \\ ${ }^{a}$ Universidade do Porto, Porto, Distrito do Porto, Portugal \\ $\&{ }^{b}$ Universidade Salgado de Oliveira - Universo, Niterói, Rio de Janeiro, Brasil
}

\begin{abstract}
Resumo
Apresentaram-se neste trabalho dois estudos relativos à validação e adaptação transcultural Escala Multidimensional de Atitudes Face a Lésbicas e a Gays (EMAFLG; Gato, Fontaine, \& Carneiro, 2012). Este instrumento é constituído por 27 itens distribuídos por quatro dimensões: Rejeição da proximidade; Homopatologização; Heterossexismo moderno; Suporte. No primeiro estudo, testou-se esta estrutura numa amostra de estudantes universitários portugueses $(N=425)$, através de Análise Fatorial Confirmatória. A maioria dos itens apresentou pesos fatoriais elevados e significativos e o modelo apresentou um ajustamento global aceitável $\left(\chi^{2} / g l=2,35 ; \mathrm{CFI}=0,93\right.$; RMSEA $=0,056$; $\mathrm{SRMR}=0,04)$; os indicadores de validade convergente e discriminante também se mostraram satisfatórios, ficando demonstrada a validade de constructo do instrumento. No segundo estudo, com o propósito de verificar em que medida a EMAFLG tinha um significado equivalente noutro país de língua oficial portuguesa, realizou-se o teste da invariância do instrumento, junto de uma amostra de estudantes universitários brasileiros $(N=420)$, recorrendo à Análise Fatorial Confirmatória Multigrupos. Os resultados sugeriram a aplicabilidade da EMAFLG em amostras de estudantes universitários nos dois países.

Palavras-chave: Homossexualidade, preconceito, atitudes sexuais, análise fatorial confirmatória.
\end{abstract}

\begin{abstract}
In this work two studies regarding the validation and transcultural adaptation of the Multidimensional Scale of Attitudes towards Lesbians and Gay Men (EMAFLG; Gato, Fontaine, \& Carneiro, 2012) were presented. The instrument is composed by 27 items distributed in four dimensions: Rejection of Proximity, Pathologization of Homosexuality, Modern Heterosexism, and Support. In the first study, the structure was tested in a sample of Portuguese university students $(N=425)$ using Confirmatory Factor Analysis. Most of the items presented high and significant factor loadings and the model showed a reasonable global fit $\left(\chi^{2} / g l=2.35 ; \mathrm{CFI}=.93 ; \mathrm{RMSEA}=.056\right.$; $\left.\mathrm{SRMR}=.04\right)$. The indicators of convergent and discriminant validity were also satisfactory, and the construct validity of the instrument was established. In the second study, with the goal of verifying to what extent the EMAFLG had an equivalent meaning in another Portuguese-speaking country, its invariance was tested through Multigroup Confirmatory Factor Analysis, using a sample of Brazilian university students $(N=420)$. Results suggested the applicability of the instrument in samples of university students from both countries.
\end{abstract}

Keywords: Homosexuality, prejudice, sexual attitudes, confirmatory factor analysis.

Nas sociedades ditas desenvolvidas observa-se uma crescente visibilidade e acesso de Gays, Lésbicas, Bissexuais e Transgêneros (pessoas GLBT) a determinados direitos civis (Andersen \& Fetner, 2008; Carneiro \& Menezes, 2007; Costa, Pereira, Oliveira, \& Nogueira, 2010; Vale de
Almeida, 2010). Contudo, o preconceito e a discriminação em função da orientação sexual persistem (Anjos, 2002; Comissão Europeia, 2008, 2009; Herek, 2009; Nogueira \& Oliveira, 2010), com efeitos adversos para o bem-estar destas pessoas. Salientem-se, a este respeito, as taxas altas
* Endereço para correspondência: Centro de Psicologia Diferencial, Faculdade de Psicologia e de Ciências da Educação, Universidade do Porto, Rua Alfredo Allen, 4200-135. E-mail: jorgegato@fpce.up.pt

Agradecimentos: Este trabalho foi financiado por uma bolsa de doutoramento atribuída ao primeiro autor pela Fundação para a Ciência e Tecnologia (SFRH/ $\mathrm{BD} / 41752 / 2007)$. Os autores agradecem a Alessandro André Leme (docente da Universidade Federal Fluminense -UFF), pela colaboração no processo de coleta de dados. 
de suicídio e tentativas de suicídio encontradas em adolescentes e adultos não heterossexuais (Haas et al., 2011; Marshal et al., 2011).

Perante este cenário, foi objetivo deste trabalho validar um instrumento de avaliação de atitudes relativamente a lésbicas e a gays, em duas culturas falantes do português, isto é, Portugal e Brasil. Assim, revê-se, em primeiro lugar, a situação social respeitante às orientações sexuais não normativas nestes dois países. Em segundo lugar, revisa-se algumas das abordagens psicológicas a este tipo de preconceito. Em terceiro lugar, descreve-se sucintamente o processo prévio de construção da Escala de Multidimensional de Atitudes Face a Lésbicas e a Gays (EMAFLG; Gato, Fontaine, \& Carneiro, 2012). Finalmente, apresentamos as análises estatísticas de validação do instrumento.

\section{Preconceito Antihomossexual dos Dois Lados do Atlântico}

Dados de um inquérito sobre valores realizado periodicamente em vários países do mundo (World Values Survey, 1997, 1999) indicam uma situação preocupante no que diz respeito ao preconceito antihomossexual, em Portugal e no Brasil. Assim, as médias de resposta à questão, "Em que medida considera a homossexualidade justificável?" (em que 1 corresponde a nada jusficável e 10 a sempre justificável) são, para os dois países, de 3,2, o que aponta para um predomínio de atitudes negativas.

Em Portugal, não obstante importantes alterações legislativas ocorridas na última década (por exemplo, acesso ao casamento civil entre pessoas do mesmo sexo em 2010), é ainda possível encontrar atitudes bastante preconceituosas face a pessoas GLBT. Assim, comparativamente com a média europeia, os portugueses sentem-se menos confortáveis com a ideia de ter um/a vizinho/a homossexual, com a presença de uma pessoa homossexual no cargo político elegível mais elevado do país e apresentam ainda uma probabilidade mais baixa de ter uma pessoa amiga ou conhecida homossexual (Comissão Europeia, 2009). Os portugueses parecem ter consciência desta situação: cerca de $60 \%$ considera que a orientação não heterossexual é um fator de discriminação comum no seu país (valor médio para a Europa de 47\%; Comissão Europeia, 2009). Tendo em conta a percepção dos próprios alvos do preconceito, um inquérito a 972 pessoas com orientações e identidades de gênero não normativas (Oliveira, Pereira, Costa, \& Nogueira, 2010) revelou que estas expressavam uma percepção elevada de discriminação, quer a nível geral, quer em setores específicos como a Justiça, a Educação, a Segurança Social e a Saúde.

Quanto à situação brasileira, algumas ações judiciais movidas por grupos de ativistas GLBT têm redundado em mudanças legislativas, como, por exemplo, a extensão de benefícios de pensão por morte e auxílio-reclusão aos casais de pessoas do mesmo sexo e a abertura de precedentes jurisprudenciais relacionados com direitos de parentalidade de pessoas homossexuais (Conselho Nacional de Combate à Discriminação [CNCD], 2004). No entanto, os crimes de ódio contra pessoas GLBT são um dos problemas com que o Brasil se continua a debater. Neste sentido, os resultados de um estudo realizado no Rio de Janeiro, envolvendo 416 gays, lésbicas e transgêneros (Carrara, Ramos, \& Caetano, 2002, citados em CNCD, 2004) revelaram que $60 \%$ dos entrevistados já tinham sido vítimas de algum tipo de agressão motivada pela orientação sexual ou identidade de género. Os resultados da pesquisa "Juventudes e sexualidade" (Castro, Abramovay, \& Silva, 2004), realizada em 14 capitais brasileiras, apontaram, efetivamente, para níveis preocupantes de preconceito contra as pessoas GLBT. Por exemplo, 25\% dos estudantes inquiridos não gostariam de ter um colega de classe homossexual (resposta maioritariamente emitida por estudantes do sexo masculino). Num outro estudo, verificou-se que $92 \%$ das pessoas inquiridas $(N=2012$ adultos de cinco regiões do Brasil) eram da opinião que existe preconceito contra pessoas GLBT (Venturi, 2009). O preconceito contra a homossexualidade foi patente nas percentagens de concordância com as seguintes afirmações, "A homossexualidade é uma doença que precisa de ser tratada" (40\%), "Quase sempre os homossexuais são promíscuos" (45\%), "Casais de gays ou lésbicas não deveriam andar abraçados ou ficar se beijando em lugares públicos" (50\%), "Casais de gays ou lésbicas não deveriam criar filhos" (47\%), "A homossexualidade é safadeza e falta de caráter" (37\%) e "Os gays são os principais culpados pelo fato da AIDS estar se espalhando pelo mundo" (34\%). Nesta medida, como referiram Almeida e Crillanovick (1999), no Brasil "ser ou não ser homossexual ainda é uma questão bem mais aflitiva que ser ou não negro, deficiente físico, mulher" (p. 167). Revisto o contexto social respeitante à homossexualidade em Portugal e no Brasil, veremos seguidamente como a Psicologia se ocupou deste tipo de preconceito.

\section{Abordagens Psicológicas do Preconceito Contra Lésbicas e Gays}

A homossexualidade foi removida do manual de diagnóstico de perturbações mentais da Associação Americana de Psiquiatria em 1973, subscrevendo a Associação Americana de Psicologia esse posicionamento dois anos mais tarde (Clarke, Ellis, Peel, \& Riggs, 2010). Sensivelmente a partir deste fato, o foco de estudo deixou, então, de ser a homossexualidade enquanto perturbação, para passar a ser o contexto de vida das pessoas não heterossexuais e o preconceito de que são vítimas (Morin, 1977). O interesse da Psicologia pelo estudo do preconceito antihomossexual tem crescido ao longo das últimas quatro décadas, sendo o construto mais disseminado o de homofobia. Este termo foi popularizado por Weinberg (1972), significando “o pânico de partilhar um mesmo espaço com homossexuais - e no caso dos próprios homossexuais, a autoaversão" (p. 4). A homofobia era aqui entendida como uma espécie de medo irracional que os heterossexuais poderiam experienciar diante das pessoas homossexuais, bem como o autodes- 
Gato, J., Fontaine, A. M. \& Leme, V. B. R. (2014). Validação e Adaptação Transcultural da Escala Multidimensional de Atitudes Face a Lésbicas e a Gays.

prezo que lésbicas e gays poderiam sentir por si próprios. Tendo o mérito de ter deslocado o foco de problematização da homossexualidade para o preconceito contra a homossexualidade, o constructo homofobia não tardou, no entanto, a ser criticado. Em primeiro lugar, dado que as reações contra as pessoas homossexuais se caracterizam mais por hostilidade do que por medo, diversos autores questionaram o seu caráter fóbico (Herek, 1994; Hudson \& Ricketts, 1980). Como salientou Carneiro (2009) o sufixo fobia "deixa em aberto a noção de uma repulsa a que não pode fugir-se, de um medo incontrolável (fóbico) que, portanto demite gratuitamente de responsabilidades quem a exerce" (p. 77). Kitzinger (1987) argumentou, por sua vez, que a homofobia se limitava a inverter a perspectiva médica, isto é, os doentes deixavam de ser os gays e as lésbicas para passarem a ser as pessoas intolerantes. Em segundo lugar, o conceito de homofobia remete a discriminação contra as pessoas homossexuais para o plano individual, ignorando os mecanismos ideológicos em que esta radica, nomeadamente a sua relação com o sexismo. A este propósito, Kite e Deaux (1987) propuseram o conceito de "sistema generalizado de crenças de género" para explicar a relação entre homofobia e atitudes face aos papéis de género. De acordo com as autoras, além de (a) um conjunto de opiniões acerca dos homens e das mulheres, (b) estereótipos sobre a masculinidade e a feminilidade, e (c) atitudes acerca dos papéis apropriados para homens e mulheres, este sistema de crenças inclui ainda percepções acerca daquelas pessoas que presumivelmente violam os papéis de género tradicionais, incluindo as lésbicas e os gays. Assim, muitas pessoas detêm teorias implícitas que fazem equivaler a homossexualidade a uma inversão de género. Nesta medida, espera-se que os gays se pareçam às mulheres heterossexuais e as lésbicas aos homens heterossexuais, não apenas no que diz respeito à atração sexual, mas também em termos de traços de personalidade, interesses, aptidões e comportamentos. As atitudes negativas têm, assim, as suas raízes numa percepção de uma violação dos papéis de género tradicionais, pelo que as pessoas que aderem a papéis de género mais conservadores são também as mais homofóbicas (Kite \& Whitley, 1998).

Para captar mais a dimensão ideológica, do que propriamente individual, do preconceito contra lésbicas e gays, o termo heterossexismo começou a ser utilizado de forma análoga ao sexismo e ao racismo. Foi Morin (1977) quem propôs este conceito, definindo-o como o "sistema de crenças que valoriza a heterossexualidade como mais 'natural' que e/ou superior à homossexualidade" (p. 629). Dado o foco macro-histórico e sociológico do heterossexismo, Herek (2000) considerou que, conceitualmente, este termo não era ainda o substituto ideal para a homofobia. Assim, o autor (2000) sugeriu que a análise científica da psicologia das atitudes antihomossexuais deve recorrer ao termo preconceito sexual. Este se refere, em termos gerais, a todas as atitudes negativas baseadas na orientação sexual, tenha o alvo uma orientação homossexual, bissexual ou heterossexual. Contudo, perante a organização atual da sexualidade, este preconceito é predominantemente dirigido às pessoas que têm um comportamento homossexual, que se identificam como gays, lésbicas ou bissexuais ou às próprias comunidades GLBT. De acordo com Herek, o constructo apresenta ainda as seguintes vantagens: ao contrário do termo homofobia, não veicula assunções apriorísticas sobre as origens, dinâmica e motivações subjacentes às atitudes antihomossexuais; liga explicitamente o estudo da hostilidade antihomossexual à longa tradição da investigação em psicologia social sobre o preconceito; não tem subjacentes juízos de valor de que as atitudes negativas relativamente às pessoas não heterossexuais são inerentemente irracionais. Mais recentemente, Herek (2007) afastou-se da abordagem clássica do preconceito, patente no constructo preconceito sexual, sugerindo alternativamente o termo estigma sexual (para uma revisão histórica da investigação psicológica nesta área ver, por exemplo, Gato, Carneiro, \& Fontaine, 2011).

Não obstante as contribuições anteriores, os modelos teóricos da psicologia social têm-se centrado, sobretudo, no preconceito racial/étnico, prestando menor atenção às pessoas com orientações sexuais minoritárias (Quiles del Castillo, Betancor Rodríguez, Rodríguez Torres, Rodríguez Pérez, \& Coello Martel, 2003). Tendo-se verificado que as formas tradicionais e hostis de racismo estavam progressivamente a ser substituídas por atitudes mais sutis e matizadas surgem, a partir dos anos 1970, novas teorias que pretendem dar conta das expressões contemporâneas do preconceito racial/étnico (Gaertner \& Dovidio, 2000; McConahay, 1986; Meertens \& Pettigrew, 1999; Pettigrew \& Meertens, 1995). Algumas destas conceitualizações foram utilizadas para explicar as modificações que também se têm observado na expressão do preconceito contra as pessoas não heterossexuais. Por exemplo, Lacerda, Pereira e Camino (2002) aplicaram o modelo do preconceito racial sutil/flagrante ao estudo do preconceito contra pessoas homossexuais, relacionando-o com a adesão a cinco possíveis explicações da homossexualidade (origem biológica, psicológica, psicossocial, religiosa, ou ético-moral). Os resultados evidenciaram que, ao passo que os igualitários eram alunos de psicologia e davam, sobretudo, explicações psicossociais da homossexualidade, os preconceituosos sutis estudavam medicina, discordavam das explicações ético-morais e aderiam a explicações biológicas e psicológicas. Já os preconceituosos flagrantes eram estudantes de engenharia civil, que concordavam com explicações religiosas e ético-morais e discordavam das psicossociais. Mais recentemente, C. R. Pereira, Torres, Pereira e Campos (2011) obtiveram resultados semelhantes junto de uma amostra de estudantes de teologia: o preconceito sutil estava relacionado com a crença numa natureza biológica e psicossocial e com a descrença numa representação ético-moral da homossexualidade; por sua vez, o preconceito flagrante estava relacionado com a descrença na natureza biológica e psicossocial e com uma representação ético-moral. Ainda no âmbito da perspectiva do preconceito flagrante e sutil, A. Pereira, Monteiro e Camino (2009a) 
procuraram verificar em que medida a adesão à norma antipreconceito reduzia efetivamente a expressão do preconceito contra as pessoas homossexuais. Os resultados evidenciaram que a pressão normativa elevada reduzia o preconceito flagrante, mas não o preconceito sutil.

No que diz especificamente respeito à construção/ adaptação de escalas de mensuração deste tipo de preconceito em língua portuguesa, baseando-se no trabalho de Pettigrew e Meertens (1995), pensado originalmente para avaliar as novas formas de preconceito racial/étnico, A. Pereira, Monteiro e Camino (2009b) validaram uma escala de preconceito contra pessoas homossexuais, composta por três fatores (rejeição a relações de proximidade, expressão de emoções positivas e expressão de emoções negativas). Por sua vez, Cerqueira-Santos, Winter, Salles, Longo e Teodoro (2007) desenvolveram a Escala de Crenças sobre Homossexualidade, composta por um fator negativo (Representação negativa de gays e lésbicas), um fator positivo (Representação positiva de gays e lésbicas) e um fator que revela uma postura mais ponderada em relação à homossexualidade (Diferença intragrupal de gays e lésbicas).

Contudo, como procuraram demonstrar Gato e cols. (2011) e Gato e cols. (2012), além de coexistirem atualmente diversos tipos de atitudes face a lésbicas e a gays, o preconceito contra estas pessoas tem especificidades que o distinguem das formas contemporâneas de preconceito racial/étnico. Adicionalmente, as atitudes face a esta população podem revestir-se de diferentes nuances, indo para além de representações positivas ou negativas. Dessa forma, com o propósito de abarcar num mesmo instrumento a avaliação de um leque diversificado e qualitativamente diferente de atitudes face a lésbicas e a gays, não necessariamente decorrentes de uma transposição direta de modelos pensados originalmente para estudar o racismo e de aspectos negativos/positivos em relação a homossexualidade, Gato e cols. (2012) desenvolveram então a EMAFLG, cujo processo de construção e validação preliminar se aborda em seguida.

\section{Desenvolvimento da EMAFLG}

Os autores selecionaram um pool de itens provenientes de um conjunto de escalas de atitudes perante a homossexualidade: Attitudes Toward Lesbian Women/Gay Men (Herek, 1988), Index of Homophobia (Hudson \& Ricketts, 1980), Homosexuality Attitude Scale (Kite \& Deaux, 1986), Modern Homonegativity Scale (Morrison, Kenny, \& Harrington, 2005), Heterosexism Scale (Park, 2001), Modern Homophobia Scale (Raja \& Stokes, 1998) e The Homophobia Scale (Wright, Adams, \& Bernat, 1999). A partir de uma revisão da literatura e de diversos indicadores sociais sobre o preconceito antihomossexual foram hipotetizados três tipos de atitudes: homopatologização, rejeição da proximidade e heterossexismo moderno. Seis pessoas com formação em Psicologia classificaram os itens de acordo com estas dimensões. Apenas os itens que apre- sentaram um índice de concordância interjuízes superior a $80 \%$ foram selecionados. Contrariamente ao previsto, análises fatoriais exploratórias revelaram uma escala composta por quatro dimensões, que se descrevem em seguida (os itens da EMAFLG, bem como as sub-escalas a que pertencem podem ser consultados no Anexo). A sub-escala Homopatologização $(\alpha=0,86)$ diz respeito a uma atitude tradicional de condenação moral e patologização da homossexualidade. A sub-escala Rejeição da proximidade ( $\alpha$ $=0,91)$ corresponde ao preconceito na sua concepção clássica, sendo composta por itens que traduzem o evitamento do contato com lésbicas e gays em diversos contextos sociais e a manifestação de desconforto emocional na sua presença. A sub-escala Heterossexismo moderno $(\alpha=0,79)$ diz respeito a expressões contemporâneas do preconceito contra lésbicas e gays. Estas referem-se ao desempenho por estas pessoas de papéis tradicionalmente associados à heterossexualidade, como a conjugalidade e a parentalidade. Incluem-se ainda nesta sub-escala posicionamentos negativos relativamente à visibilidade ou expressão da identidade lésbica e gay e à ênfase excessiva que estas pessoas supostamente colocariam na sua sexualidade. Finalmente, a sub-escala Suporte $(\alpha=0,83)$ relaciona-se com uma atitude positiva face a lésbicas e a gays, nomeadamente no que diz respeito à legitimidade da defesa dos seus direitos. Além de revelarem elevada confiabilidade, os quatro fatores da EMAFLG correlacionaram-se de forma significativa e no sentido esperado, destacando-se o fato das duas atitudes mais negativas (Rejeição da proximidade e Homopatologização) apresentarem a correlação mais elevada $(r=0,71, p<0,001)$.

Provas adicionais da validade de constructo do instrumento foram obtidas por Gato e cols. (2012) por meio de um estudo diferencial, em função de duas variáveis que mostraram estar associadas ao preconceito antihomossexual: o gênero dos/as participantes e o seu contato interpessoal com lésbicas e gays. Assim, consistentemente com a literatura (e.g., Bowen \& Bourgeois, 2001; Cerqueira-Santos et al., 2007; Herek \& Capitanio, 1996; Iraklis, 2010; Kite \& Whitley, 1996), as participantes do sexo feminino e os/as participantes que reportaram ter amigas/ os lésbicas e gays subscreveram menos as três atitudes negativas e mais a atitude positiva da EMAFLG, do que os homens e os/as participantes que não tinham amigas/ os lésbicas e/ou gays.

É objetivo principal deste trabalho dar continuidade ao processo de validação da EMAFLG. Assim, procurou-se, num primeiro estudo, estabelecer a estrutura fatorial do instrumento junto de uma amostra de estudantes portugueses, através de Análise Fatorial Confirmatória (AFC). Este método é utilizado quando existe informação prévia sobre a estrutura fatorial que é preciso confirmar, servindo por isso para verificar se determinados fatores latentes (sub-escalas) são responsáveis pelo comportamento de determinadas variáveis manifestas específicas (itens), segundo um padrão previamente estabelecido (Marôco, 2010). 
Gato, J., Fontaine, A. M. \& Leme, V. B. R. (2014). Validação e Adaptação Transcultural da Escala Multidimensional de Atitudes Face a Lésbicas e a Gays.

Quando se aplica um instrumento de avaliação noutra cultura é fundamental verificar se o modelo de medida é invariante, isto é, se as medidas utilizadas refletem o mesmo constructo (Hui \& Triandis, 1985). Nesta medida, se a invariância de uma escala não for estabelecida, as conclusões baseadas nesse instrumento serão ambíguas ou mesmo erróneas. Por exemplo, diferenças transculturais nas médias obtidas numa determinada escala poderão dever-se a verdadeiras diferenças entre países nos constructos avaliados ou a enviesamentos sistemáticos na forma como as pessoas de diferentes países respondem a determinados itens; de forma semelhante, diferenças transnacionais nas relações entre os escores das escalas podem indicar diferenças reais nas relações estruturais entre os constructos ou dever-se, por exemplo, à diferenças nos índices de confiabilidade da escala ou mesmo à não equivalência dos constructos (Cheung \& Rensvold, 2002; Davidov, Schmidt, \& Schwartz, 2008; Harkness, Van de Vijver, \& Mohler, 2003; Marôco, 2010; Vandenberg \& Lance, 2000). Embora uma série de técnicas tenha sido proposta para avaliar diversos aspectos da equivalência de medida (Hui \& Triandis, 1985), existe um consenso geral de que a Análise Fatorial Confirmatória Multigrupos (AFCMG; Jöreskog, 1971, citado por Davidov et al., 2008; Marôco, 2010) é a abordagem mais eficaz para testar a invariância de medida transcultural. Procurou-se, assim, num segundo estudo, verificar em que medida as atitudes face a lésbicas e a gays, conforme mensuradas pela EMAFLG, tinham um significado equivalente em Portugal e no Brasil, através de uma AFCMG.

\section{Estudo 1: Validação da EMAFLG}

Neste estudo, analisou-se a validade de constructo do instrumento nos seus três componentes: fatorial, convergente e discriminante (Anastasi \& Urbina, 1997).

\section{Método}

\section{Participantes}

Da amostra fazem parte 425 estudantes universitários portugueses ( $71 \%$ do sexo feminino), provenientes de diversos cursos da Universidade e Instituto Politécnico do Porto (Engenharia Civil, Engenharia Mecânica, Terapia Ocupacional, Terapia da Fala, Enfermagem, Psicologia e Ciências da Educação) e da Escola Superior de Educação de Coimbra (Comunicação Organizacional), com uma idade compreendida entre os 18 e os 60 anos $(M=21,53$; $D P=5,10)$.

\section{Instrumento}

A EMAFLG é composta por 27 itens, distribuídos por quatro fatores, segundo análise fatorial exploratória (Gato et al., 2012). A Homopatologização, a Rejeição da proximidade, o Heterossexismo moderno e o Suporte são compostos respectivamente por cinco, dez, sete e cinco itens (ver Anexo). Os participantes exprimiram a sua opinião para cada um dos itens numa escala de resposta tipo Likert de 1 (discordo completamente) a 6 (concordo completamente).

\section{Procedimento}

A coleta de dados foi antecedida de Consentimento Livre e Informado. Os participantes foram esclarecidos acerca da natureza voluntária da participação e do propósito do estudo, tendo sido também assegurados a confidencialidade e o anonimato das respostas. Após permissão das respectivas instituições de ensino superior, os questionários foram coletivamente administrados no período disponibilizado para o efeito, pelo primeiro autor do estudo assistido por duas psicólogas.

\section{Análise Estatística}

A base de dados foi construída no PASW Statistics 18.0 (SPSS Inc., Chicago, IL). A validade fatorial foi determinada através de uma AFC, com recurso ao software AMOS (v. 19, SPSS Inc., Chicago, IL). Os parâmetros foram estimados com base na matriz de correlações, recorrendo-se ao método da máxima verosimilhança. Analisou-se a existência de outliers multivariados através da distância quadrada de Mahalanobis $\left(\mathrm{D}^{2} ; p 1\right.$ e $\left.p 2<0,001\right)$ e a normalidade das variáveis foi verificada através dos coeficientes de assimetria ( $s k)$ e curtose $(k u)$, com valores de $|\mathrm{Sk}|>3$ indicadores de assimetria severa; valores de $|\mathrm{Ku}|>10$ indicadores de curtose severa e $|\mathrm{Ku}|>20$ de curtose muito severa (Kline, 2011). O ajustamento global do modelo hipotetizado foi avaliado através do seguinte conjunto de índices e respectivos valores de referência para um ajustamento aceitável (Kline, 2011; Schweizer, 2010): rácio $\chi^{2} / g l<5$ (Arbuckle, 2008); Bentler Comparative Fit Index - CFI > 0,90 (Bentler, 1990), Root Mean Square Error of Approximation - RMSEA $<0,08$ (Arbuckle, 2008) e Standardized Root Mean Square Residual - SRMR $<0,08$ (Hu \& Bentler, 1999 citados em Kline, 2011). A qualidade do ajustamento local foi avaliada através dos pesos fatoriais estandardizados e dos coeficientes de confiabilidade individual dos itens com valores superiores, respectivamente, a 0,50 e 0,25 , indicadores de um bom ajustamento e, portanto, da validade fatorial do modelo (Marôco, 2010). A validade convergente, que ocorre quando os itens que constituem cada um dos fatores apresentam correlações positivas e elevadas entre si, foi avaliada através do cálculo da confiabilidade compósita (FC) e da variância extraída média (VEM) de cada fator (Fornell \& Larcker, 1981, citados por Marôco, 2010), com FC >0,70 e VEM > 0,50, indicadoras de uma validade convergente adequada (Hair, Anderson, Tatham, \& Black, 1988, citados por Marôco, 2010). A validade discriminante, que acontece quando o constructo em análise não se encontra correlacionado com constructos que operacionalizam constructos diferentes, foi avaliada através da comparação do modelo com correlações entre fatores livres com um modelo restrito com a correlação entre os fatores em estudo fixada em 1 (Anderson \& Gerbin, 1988, citados por Marôco, 2010). 


\section{Resultados e Discussão}

\section{Validade Fatorial}

Em primeiro lugar, a sensibilidade psicométrica dos itens da EMAFLG foi analisada a partir da sua distribuição. Todos os itens apresentaram valores de assimetria e curtose que não diferiam marcadamente da Distribuição
Normal (Kline, 2011). As estatísticas descritivas relativas a cada um dos itens podem ser consultadas na Tabela 1.

Antes de se proceder à AFC, os valores omissos foram imputados através do método da regressão linear. Os quatro fatores da EMAFLG foram especificados como variáveis latentes e as correlações entre os mesmos especificadas para serem estimadas livremente, tendo-se obtido índices de ajustamento aceitáveis (Figura 1$)^{1}$.

Tabela 1

Estatísticas Descritivas da EMAFLG nas Amostras Portuguesa e Brasileira (valores dentro de parênteses)

\begin{tabular}{|c|c|c|c|c|c|c|c|c|c|c|}
\hline \multirow{2}{*}{$\frac{\text { Item }}{\text { It1 }}$} & \multicolumn{2}{|c|}{$M$} & \multicolumn{2}{|c|}{$\mathrm{Me}$} & \multicolumn{2}{|c|}{$D P$} & \multicolumn{2}{|c|}{$\mathrm{Ku}$} & \multicolumn{2}{|c|}{ Sk } \\
\hline & 4,88 & $(4,47)$ & 5 & $(5)$ & 1,29 & $(1,52)$ & 0,51 & $(-0,77)$ & $-1,09$ & $(-0,60)$ \\
\hline It2 & 1,93 & $(2,31)$ & 1 & (2) & 1,36 & $(1,51)$ & 1,19 & $(-0,45)$ & 1,46 & $(0,84)$ \\
\hline It3 & 4,51 & $(4,91)$ & 5 & (5) & 1,51 & $(1,41)$ & $-0,20$ & $(0,88)$ & $-0,88$ & $(-1,31)$ \\
\hline It 4 & 1,84 & $(2,05)$ & 1 & (2) & 1,22 & $(1,29)$ & 1,55 & $(0,02)$ & 1,50 & $(1,02)$ \\
\hline It5 & 3,36 & $(2,86)$ & 4 & (3) & 1,70 & $(1,76)$ & $-1,27$ & $(-1,20)$ & 0,04 & $(0,41)$ \\
\hline It6 & 1,85 & $(1,75)$ & 1 & (1) & 1,33 & $(1,30)$ & 1,71 & $(2,77)$ & 1,62 & $(1,89)$ \\
\hline It7 & 4,38 & $(3,93)$ & 5 & (4) & 1,42 & $(1,67)$ & $-0,28$ & $(-1,10)$ & $-0,73$ & $(-0,29)$ \\
\hline It8 & 4,19 & $(3,90)$ & 4 & (4) & 1,38 & $(1,55)$ & $-0,44$ & $(-0,78)$ & $-0,48$ & $(-0,38)$ \\
\hline It9 & 5,02 & $(4,82)$ & 6 & (6) & 1,35 & $(1,59)$ & 1,47 & $(0,26)$ & $-1,48$ & $(-1,21)$ \\
\hline It10 & 2,20 & $(2,25)$ & 2 & (2) & 1,38 & $(1,57)$ & 0,14 & $(0,05)$ & 1,04 & $(1,10)$ \\
\hline It11 & 4,56 & $(4,87)$ & 5 & $(5)$ & 1,28 & $(1,42)$ & 0,63 & $(0,71)$ & $-0,94$ & $(-1,24)$ \\
\hline It12 & 2,27 & $(2,32)$ & 2 & (2) & 1,31 & $(1,50)$ & $-0,33$ & $(-0,44)$ & 0,86 & $(0,85)$ \\
\hline It13 & 3,87 & $(4,54)$ & 4 & (5) & 1,73 & $(1,59)$ & $-1,09$ & $(-0,25)$ & $-0,39$ & $(-0,92)$ \\
\hline It14 & 4,42 & $(4,45)$ & 5 & $(5)$ & 1,36 & $(1,56)$ & 0,10 & $(-0,15)$ & $-0,82$ & $(-0,89)$ \\
\hline It 15 & 4,99 & $(5,19)$ & 5 & (6) & 1,27 & $(1,26)$ & 1,42 & $(2,59)$ & $-1,40$ & $(-1,76)$ \\
\hline It16 & 5,16 & $(5,38)$ & 6 & $(6)$ & 1,15 & $(1,05)$ & 1,95 & $(4,57)$ & $-1,53$ & $(-2,09)$ \\
\hline It17 & 4,63 & $(4,91)$ & 5 & (5) & 1,13 & $(1,31)$ & 1,59 & $(1,27)$ & $-1,13$ & $(-1,33)$ \\
\hline It18 & 1,96 & $(2,11)$ & 2 & (1) & 1,22 & $(1,50)$ & 0,60 & $(0,37)$ & 1,21 & $(1,23)$ \\
\hline It19 & 3,47 & $(2,66)$ & 3 & (2) & 1,61 & $(1,64)$ & $-1,04$ & $(-0,76)$ & 0,04 & $(0,65)$ \\
\hline It 20 & 2,04 & $(2,25)$ & 2 & (2) & 1,21 & $(1,43)$ & 1,34 & $(0,38)$ & 1,29 & $(1,08)$ \\
\hline It 21 & 2,15 & $(2,34)$ & 2 & (2) & 1,40 & $(1,59)$ & $-0,21$ & $(-0,37)$ & 0,98 & $(0,92)$ \\
\hline It 22 & 1,65 & $(1,75)$ & 1 & (1) & 1,13 & $(1,22)$ & 3,51 & $(2,56)$ & 1,96 & $(1,76)$ \\
\hline It 23 & 1,49 & $(1,38)$ & 1 & (1) & 0,96 & $(0,89)$ & 6,31 & $(11,50)$ & 2,44 & $(3,17)$ \\
\hline It 24 & 1,93 & $(1,71)$ & 1 & (1) & 1,30 & $(1,25)$ & 1,66 & $(3,46)$ & 1,49 & $(2,01)$ \\
\hline It 25 & 4,93 & $(4,49)$ & 5 & $(5)$ & 1,09 & $(1,52)$ & 2,94 & $(-0,12)$ & $-1,50$ & $(-0,89)$ \\
\hline It 26 & 3,30 & $(3,19)$ & 3 & (3) & 1,54 & $(1,71)$ & $-0,87$ & $(-1.19)$ & 0,08 & $(0,18)$ \\
\hline It 27 & 4,56 & $(4,12)$ & 5 & (4) & 1,22 & $(1,55)$ & 0,48 & $(-0,60)$ & $-0,87$ & $(-0,55)$ \\
\hline
\end{tabular}

Todos os itens pertencentes ao fator Rejeição da proximidade apresentaram saturações de sinal inverso às obtidas na AFE (Gato et al., 2012). Nesta medida, procedeu-se à recodificação de quatro itens que, saturando positivamente
${ }^{1} \mathrm{~A}$ inspeção aos valores de $\mathrm{DM}^{2}$ sugeriu que 32 observações eram outliers pelo que se realizou uma nova AFC sem estes casos. Como os índices de ajustamento não diferiram dos já obtidos, optou-se por manter a solução encontrada anteriormente. 
Gato, J., Fontaine, A. M. \& Leme, V. B. R. (2014). Validação e Adaptação Transcultural da Escala Multidimensional de Atitudes Face a Lésbicas e a Gays.

AFC da EMAFLG (Portugal)

$\mathrm{X} 2(318)=748,033 ; \mathrm{X} 2 / \mathrm{gl}=2,352 ; \mathrm{p}=, 000 ; \mathrm{CF}=, 927 ; \mathrm{SRMR}=, 049$ RMSEA $=, 056 ;$ I.C. $90 \%=], 051,062[$

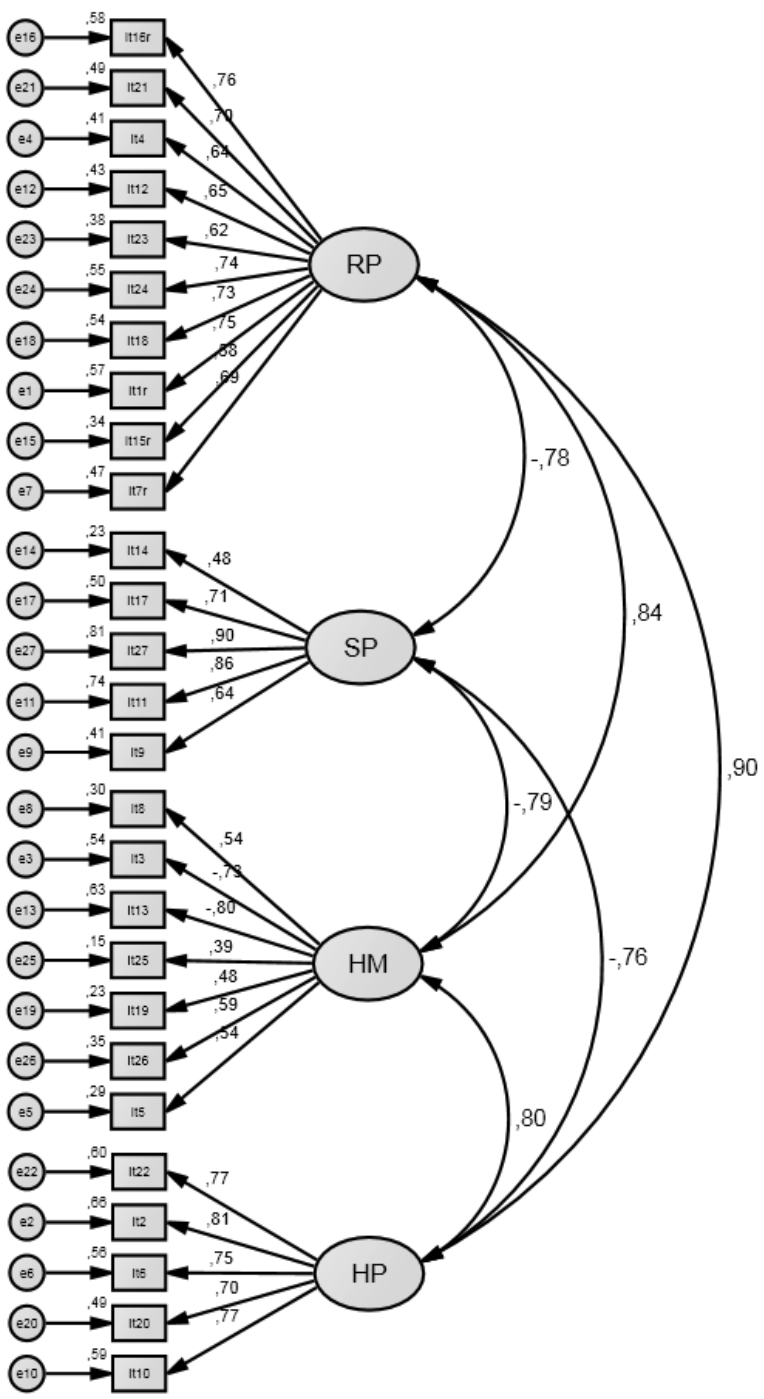

Figura 1. Análise fatorial confirmatória da EMAFLG na amostra portuguesa $(N=425)$.

no fator, iam no sentido oposto ao teoricamente esperado (itens $1,7,15$ e 16). No que diz respeito ao ajustamento local, à exceção de três itens, todos os outros apresentaram pesos fatoriais e coeficientes de confiabilidade individual aceitáveis. Os itens 14 e 19 apresentaram valores bastante próximos do aceitável, sendo o item 25 o mais problemático. Efetivamente, a afirmação "Quando ouço falar numa relação amorosa, parto do princípio que são duas pessoas do sexo oposto", não traduz claramente um preconceito. No entanto, não deixa de refletir uma das componentes da expressão do preconceito contra lésbicas e gays que se verifica atualmente, nomeadamente no que diz respeito à (in)visibilidade ou ignorar da identidade lésbica e gay (Gato et al., 2012). Considerou-se, portanto, que este item não comprometia a validade fatorial do instrumento, optando-se pela sua manutenção.

\section{Validade Convergente}

Demonstrada a adequação da estrutura fatorial proposta à amostra em estudo, procedeu-se à avaliação da validade convergente do instrumento. Esta revelou-se aceitável para os fatores Suporte $(\mathrm{FC}=0,85$; VEM $=0,54)$ e Homopatologização $(\mathrm{FC}=0,87 ; \mathrm{VEM}=0,57)$, sendo próxima do aceitável para os fatores Rejeição da proximidade $(\mathrm{FC}=$ $0,90 ; \mathrm{VEM}=0,48)$ e Heterossexismo moderno $(\mathrm{FC}=0,79$; $\operatorname{VEM}=0,35)$. $O$ valor da $\operatorname{VEM}(0,35)$ para o Heterossexismo moderno é indicador de que o comportamento dos itens que compõem este fator só é parcialmente explicado pelo mesmo. De fato, deste fator fazem parte dois itens (19 e 25), com um peso fatorial inferior a 0,50 (Figura 1) que dizem respeito a posicionamentos relativamente à visibilidade e expressão da identidade lésbica e gay. Conclui-se que esta é provavelmente uma expressão menos forte do fator Heterossexismo moderno do que as afirmações relativas à conjugalidade e à parentalidade. Para explicar este fenómeno concorre o fato de os debates em torno do casamento e da adoção por casais do mesmo sexo estarem na ordem do dia, no momento em que o instrumento foi construído (Gato et al., 2012), assumindo estas questões maior relevância na expressão do fator Heterossexismo moderno.

\section{Validade Discriminante}

Por refletirem diferentes facetas das atitudes face a lésbicas e a gays, justificam-se as correlações elevadas que se verificaram entre os fatores que compõem a EMAFLG (entre 0,76 e 0,90 ). Adicionalmente, o fato de amostra utilizada ser bastante homogênea em termos etários e educacionais pode ter contribuído para este fenômeno. Ainda assim, constatou-se que todas as correlações eram significativamente diferentes de 1 (testes da diferença do $\chi^{2}$ significativos), ficando demonstrada a validade discriminante (Tabela 2).

Em síntese, a maioria dos itens apresentou pesos fatoriais elevados e significativos no fator para o qual foram especificados e o modelo apresentou um ajustamento global aceitável. Os indicadores de validade convergente e discriminante também se mostraram satisfatórios, ficando demonstrada a validade de constructo da EMAFLG.

\section{Estudo 2: Adaptação Transcultural}

$\mathrm{O}$ teste da invariância de um determinado modelo fatorial compreende dois passos: (a) análise do modelo fatorial em cada um dos grupos individualmente; e (b) análise multigrupos (Marôco, 2010). Dado que a validade fatorial da EMAFLG já foi analisada na amostra portuguesa, o mesmo será feito na amostra brasileira; só depois de procederá à análise multigrupos.

\section{Método}

\section{Participantes}

Utilizou-se neste estudo uma amostra de 420 estudantes universitários brasileiros (54\% do sexo feminino), pro- 
Psicologia: Reflexão e Crítica, 27(2), 257-271.

Tabela 2

Comparação do Modelo Livre com os Modelos com Correlações entre Fatores Fixas em 1 (Portugal)

\begin{tabular}{|c|c|c|c|c|}
\hline Modelos & $\chi^{2}$ & $g l$ & $\Delta \chi^{2}$ & $\Delta \mathrm{gl}$ \\
\hline Modelo 1: Modelo livre & $720,30 *$ & 318 & & \\
\hline Modelo 2: Correlação entre F1 e F2 fixa em 1 & $765,83 *$ & 319 & & \\
\hline Modelo 2 vs. Modelo 1 & & & $45,53^{*}$ & 1 \\
\hline Modelo 3: Correlação entre F1 e F3 fixa em 1 & $1371,42 *$ & 319 & & \\
\hline Modelo 3 vs. Modelo 1 & & & $651,12^{*}$ & 1 \\
\hline Modelo 4: Correlação entre F1 e F4 fixa em 1 & $1400,04 *$ & 319 & & \\
\hline Modelo 4 vs. Modelo 1 & & & $678,74 *$ & 1 \\
\hline Modelo 5: Correlação entre F2 e F3 fixa em 1 & $1332,13^{*}$ & 319 & & \\
\hline Modelo 5 vs. Modelo 1 & & & $611,83^{*}$ & 1 \\
\hline Modelo 6: Correlação entre F2 e F4 fixa em 1 & $1353,89 *$ & 319 & & \\
\hline Modelo 6 vs. Modelo 1 & & & $633,59^{*}$ & 1 \\
\hline Modelo 7: Correlação entre F3 e F4 fixa em 1 & $753,17^{*}$ & 319 & & \\
\hline Modelo 7 vs. Modelo 1 & & & $32,87^{*}$ & 1 \\
\hline
\end{tabular}

$*_{p}<0,001$.

venientes de diversos cursos da Universidade Federal de Uberlândia (Medicina, Direito, Ciências Sociais, Pedagogia e Engenharia Mecânica), com uma idade compreendida entre os 17 e os 54 anos $(M=20,59 ; D P=4,05)$.

\section{Procedimento}

O procedimento de coleta de dados foi o mesmo utilizado no estudo anterior. Os questionários foram coletivamente administrados no período disponibilizado para o efeito, pela segunda autora do estudo.

\section{Instrumento}

Antes de ser aplicada à amostra brasileira, a EMAFLG foi sujeita a um processo de reflexão falada junto de seis pessoas de nacionalidade brasileira, após o que foram realizados alguns ajustes semânticos para facilitar a compreensão dos itens (consultar alterações efetuadas no Anexo).

\section{Análise Estatística}

A base de dados foi construída no PASW Statistics 18.0 (SPSS Inc., Chicago, IL). A AFC e a AFCMG foram realizadas com recurso ao software AMOS (v. 19, SPSS Inc., Chicago, IL). Para a avaliação do ajustamento dos modelos consideraram-se os índices e valores de referência utilizados no estudo anterior. Para a comparação de modelos, além do teste da diferença do $\chi^{2}$ utilizou-se o Akaike Information Criteria - AIC (quanto menor o seu valor, melhor; Arbuckle, 2008). A inspeção de outliers e os testes de normalidade efetuaram-se através dos procedimentos estatísticos utilizados no Estudo 1. A re-especificação dos modelos foi feita a partir dos índices de modificação produzidos pelo AMOS e com base em considerações teóricas. Para evitar a capitalização dos erros de tipo I, frequentes na utilização de índices de modificação, procedeu-se apenas à alteração de trajetórias para índices de modificação superiores a 11 [ $\left.\chi^{2}(1)=10,83, p<0,001\right]$. A validade convergente e a validade discriminante foram avaliadas utilizando os mesmos procedimentos e valores de referência do estudo anterior. A invariância do modelo de medida foi testada comparando-se o modelo com os parâmetros livres com um modelo constrito onde foram fixados sequencialmente nos dois grupos, (a) os pesos fatoriais, (b) as correlações entre os fatores e entre os erros, e (c) os erros. Dada a dimensão da amostra, utilizou-se como critério de invariância, não o teste da diferença do qui-quadrado, mas sim um decréscimo no valor do CFI e um acréscimo no valor do RMSEA não superiores, respectivamente, a 0,010 e a 0,015 (Chen, 2007; Cheung \& Rensvold, 2002).

\section{Resultados e Discussão}

Como já foi referido, o processo de adaptação transcultural da EMAFLG desenrolou-se em dois momentos. Antes de se proceder ao teste da invariância, estabeleceu-se, num primeiro momento, a validade de constructo do instrumento na amostra brasileira. Num segundo momento, testou-se a invariância impondo níveis crescentes de restrição à estrutura fatorial do modelo ajustado para os dois países. 
Gato, J., Fontaine, A. M. \& Leme, V. B. R. (2014). Validação e Ad a Lésbicas e a Gays.

\section{Ajustamento do Modelo na Amostra Brasileira}

Avaliou-se, em primeiro lugar, a sensibilidade psicométrica dos itens a partir da sua distribuição. Todos os itens apresentaram valores de assimetria e curtose que não diferiam marcadamente da Distribuição Normal (Tabela 1), à exceção do item 23 ("Sinto que não se pode confiar numa pessoa que é homossexual"). Este apresentou uma distribuição extremamente leptocúrtica e positivamente assimétrica, indicadora de que os participantes discordaram totalmente (valor da mediana igual a 1), na sua maioria, do seu conteúdo. Decidiu-se, ainda assim, pela manutenção do item por se considerar que o mesmo não prejudicava a validade fatorial do instrumento.

Em seguida, avaliou-se a validade de constructo nos seus três componentes (fatorial, convergente e discriminante). Antes de se proceder à $\mathrm{AFC}$, os valores omissos foram imputados através do método da regressão linear. $\mathrm{O}$ modelo apresentou um ajustamento global próximo do aceitável, $\left(\chi^{2} / g l=2,91 ; \mathrm{CFI}=0,89 ; \mathrm{RMSEA}=0,068\right.$; $\mathrm{SRMR}=0,05)^{2}$. Com o objetivo de melhorar o ajustamento do modelo, procedeu-se à sua re-especificação. Os índices de modificação mostraram a existência de 18 correlações entre erros de medida que prejudicavam o ajustamento global do modelo e que, ao ser introduzidas, levariam a uma diminuição significativa do valor de $\chi^{2}$. Do ponto de vista estatístico, os índices de modificação que mais contribuíam para o ajustamento do modelo diziam respeito às correlações entre os erros relativos aos pares de itens 15/16, 20/22 e 23/24. Do ponto de vista conceitual, verificou-se que tais correlações seriam justificadas pelo fato de estes pares de itens partilharem algo em comum (ver Anexo). Mais especificamente, os itens 15 e 16, além de serem consecutivos e pertencerem ao fator Rejeição da proximidade, iniciam-se da mesma forma ("Não me importo/importaria"); também consecutivos e pertencentes ao fator Rejeição da proximidade, os itens 23 e 24 referem-se ambos à confiança depositada numa pessoa homossexual; finalmente, os itens 20 e 22 pertencem ao fator Homopatologização e dizem respeito à mudança da orientação sexual. Como se pode verificar na Figura 2, após a introdução destas três correlações, o ajustamento global melhorou significativamente $\left(\Delta \chi_{(3)}^{2}=117,47, p<0,001\right)$, apresentando agora o modelo índices de ajustamento aceitáveis; as três correlações introduzidas eram significativas e moderadas. No que diz respeito ao ajustamento local, tal como tinha sucedido na amostra portuguesa, à exceção do item 25 todos os outros apresentaram pesos fatoriais e coeficientes de confiabilidade individual superiores, respetivamente, a 0,50 e a 0,25 . No entanto, considerou-se que com um peso fatorial de 0,42 esse item não punha em causa a validade fatorial do instrumento, optando-se pela sua manutenção.

${ }^{2} \mathrm{O}$ exame dos valores de $\mathrm{DM}^{2}$ indicou que 28 observações eram outliers pelo que se realizou uma nova AFC sem estes casos. Dado que os resultados não diferiram dos obtidos anteriormente, escolheu-se não eliminar esses participantes.

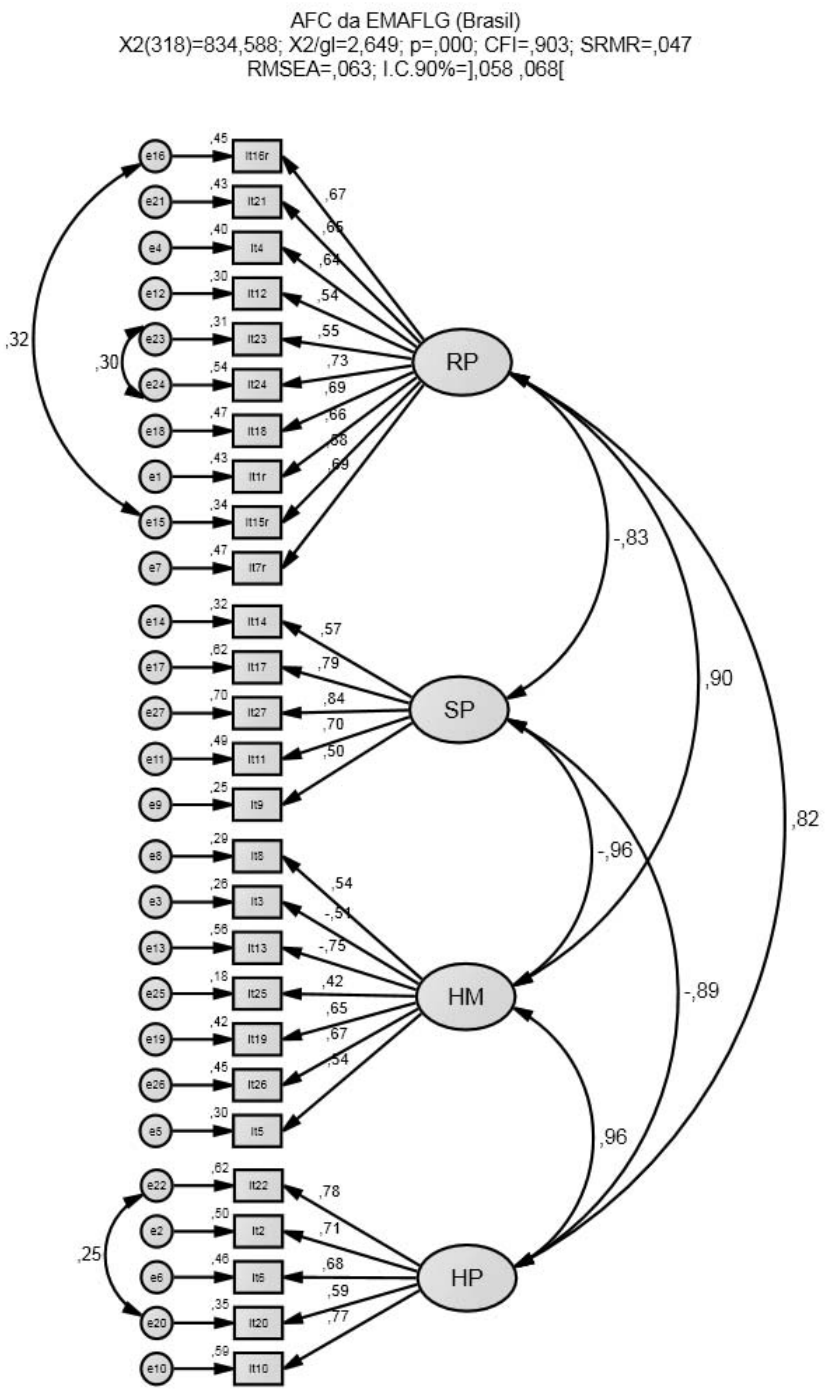

Figura 2. Análise fatorial confirmatória da EMAFLG na amostra brasileira $(N=420)$.

Demonstrada a adequação da estrutura fatorial proposta à amostra brasileira, procedeu-se à avaliação da validade convergente do instrumento. Esta revelou-se aceitável para o fator Homopatologização $(\mathrm{FC}=0,84 ; \mathrm{VEM}=0,51) \mathrm{e}$ próxima do aceitável para os fatores Suporte $(\mathrm{FC}=0,82$; $\mathrm{VEM}=0,48)$, Rejeição da proximidade $(\mathrm{FC}=0,86$; VEM $=0,41)$ e Heterossexismo moderno $(\mathrm{FC}=0,77 ; \mathrm{VEM}=$ 0,35). Embora os valores de FC de todos os fatores se tenham revelado satisfatórios, os valores baixos da VEM dos fatores Rejeição da proximidade e Heterossexismo moderno sugerem que o comportamento dos itens que compõem estes dois fatores só é parcialmente explicado pelos mesmos.

Ainda que as correlações entre os fatores se tenham revelado extremamente elevadas, constatou-se que todas eram significativamente diferentes de 1 (testes da diferença do $\chi^{2}$ significativos), ficando demonstrada a validade discriminante (Tabela 3). 
Psicologia: Reflexão e Crítica, 27(2), 257-271.

Tabela 3

Comparação do Modelo Livre com os Modelos com Correlações entre Fatores Fixas em 1 (Brasil)

\begin{tabular}{|c|c|c|c|c|}
\hline Modelos & $\chi^{2}$ & $g l$ & $\Delta \chi^{2}$ & $\Delta \mathrm{gl}$ \\
\hline Modelo 1: Modelo livre & $834,59 *$ & 315 & & \\
\hline Modelo 2: Correlação entre F1 e F2 fixa em 1 & $864,64 *$ & 316 & & \\
\hline Modelo 2 vs. Modelo 1 & & & $30,06^{*}$ & 1 \\
\hline Modelo 3: Correlação entre F1 e F3 fixa em 1 & $1527,22 *$ & 316 & & \\
\hline Modelo 3 vs. Modelo 1 & & & $692,63 *$ & 1 \\
\hline Modelo 4: Correlação entre F1 e F4 fixa em 1 & $1375,78 *$ & 316 & & \\
\hline Modelo 4 vs. Modelo 1 & & & $541,20^{*}$ & 1 \\
\hline Modelo 5: Correlação entre F2 e F3 fixa em 1 & $1549,75^{*}$ & 316 & & \\
\hline Modelo 5 vs. Modelo 1 & & & $715,16^{*}$ & 1 \\
\hline Modelo 6: Correlação entre F2 e F4 fixa em 1 & $1493,52 *$ & 316 & & \\
\hline Modelo 6 vs. Modelo 1 & & & $658,93 *$ & 1 \\
\hline Modelo 7: Correlação entre F3 e F4 fixa em 1 & $839,86^{*}$ & 316 & & \\
\hline Modelo 7 vs. Modelo 1 & & & $5,28 * *$ & 1 \\
\hline
\end{tabular}

${ }^{*} p<0,001 ; * * p<0,050$.

\section{Análise Multigrupos}

O nível menos exigente de invariância diz respeito à invariância configuracional, que requer que os itens exibam a mesma configuração de pesos fatoriais em cada um dos países. Esta análise pretende, assim, confirmar se os mesmos itens medem o mesmo constructo nas duas amostras (Horn \& McArdle, 1992, citados por Davidov et al., 2008). Com este propósito, realizou-se uma AFC para os dois países em simultâneo. Contrariamente à $\mathrm{AFC}$ conduzida em amostras separadas, esta análise parte de um modelo básico que inclui os dois grupos e produz um conjunto de estatísticas de ajustamento relativamente às quais modelos aninhados com constrangimentos sucessivos em termos de invariância serão posteriormente comparados. O modelo para os dois países apresentou um ajustamento global e local razoáveis $\left(\chi^{2} / g l=3,70 ; \mathrm{CFI}=0,92\right.$; RMSEA $=0,057 \mathrm{SRMR}=0,04)$, ficando provada a invariância configuracional.

Seguidamente, procedeu-se à AFCMG, adotando-se um procedimento stepwise no sentido de uma exigência crescente em termos do nível de invariância, isto é, fixando-se sucessivamente os pesos fatoriais, as correlações entre os fatores e os erros.

Como se pode observar na Tabela 4, as mudanças nos valores do CFI e do RMSEA foram inferiores aos valores critério adotados, exceto no que diz respeito ao modelo em que os resíduos foram fixados. No entanto, esta condição não é indispensável para se estabelecer a invariância (Ma- rôco, 2010). Em síntese, os modelos com pesos fatoriais fixos e com covariâncias entre os fatores e os erros fixadas não apresentaram um ajustamento significativamente pior do que o modelo livre, ficando assim demonstrada a invariância do modelo de medida de atitudes face a lésbicas e a gays entre Portugal e o Brasil. Este resultado é, aliás, consistente com as semelhanças encontradas no que diz respeito às atitudes face à homossexualidade que parecem existir entre os dois países (World Values Survey, 1997, 1999).

O padrão de correlações elevadas entre os diversos fatores (superiores a 0,80 ) que se verificou na amostra brasileira sugeria a existência de um fator de $2^{\mathrm{a}}$ ordem. Nesta medida, especificou-se um segundo modelo com uma estrutura fatorial composta por cinco fatores, contendo os quatro fatores de primeira ordem hipotetizados no modelo anterior e um fator latente global de $2^{\mathrm{a}}$ ordem. A hipótese testada era a de que os quatro tipos de atitudes representadas nos fatores de primeira ordem eram diferentes dimensões de um mesmo traço latente: as atitudes face a lésbicas e a gays. Sendo $\chi_{\text {dif }}^{2}=5,17<\chi_{0,95 ;(2)}^{2}=$ 5,99 , verificou-se que a qualidade de ajustamento não era significativamente diferente nos dois modelos. No entanto, por ter mais graus de liberdade e por apresentar um valor de AIC menor (959, 76 vs. 993,24), o modelo de $2^{a}$ ordem mostrou ser mais parcimonioso, o que recomenda a sua utilização. 
Gato, J., Fontaine, A. M. \& Leme, V. B. R. (2014). Validação e Adaptação Transcultural da Escala Multidimensional de Atitudes Face a Lésbicas e a Gays.

Tabela 4

Testes de Invariância da EMAFLG

\begin{tabular}{lccccccccc}
\hline \multicolumn{1}{c}{ Modelos } & $\chi^{2}$ & $G l$ & $\chi^{2} / g l$ & CFI & RMSEA & AIC & Comparação & $\Delta$ CFI & $\Delta$ RMSEA \\
\hline 1. Modelo básico & 1661,01 & 636 & 2,61 & 0,91 & 0,04 & 1901,01 & - & - & - \\
2. Pesos fatoriais fixos & 1762,93 & 659 & 2,68 & 0,90 & 0,05 & 1906,93 & 2 vs. 1 & $-0,007$ & 0,001 \\
3. Covariâncias fixas & 1831,01 & 669 & 2,74 & 0,90 & 0,05 & 2005,01 & 3 vs. 2 & $-0,005$ & 0,000 \\
4. Resíduos fixos & 2198,59 & 696 & 3,16 & 0,87 & 0,05 & 2318,59 & 4 vs. 3 & $-0,031$ & 0,006 \\
\hline
\end{tabular}

Modelo de 2a Ordem da EMAFL G (Brasil) $\mathrm{X} 2(318)=839,762 ; \mathrm{X} 2 / \mathrm{gl}=2,641 ; \mathrm{p}=000 ; \mathrm{CFI}=903 ; \mathrm{SRMR}=047$ RMSEA $=063 ;$ I C $90 \%=1,057,068$

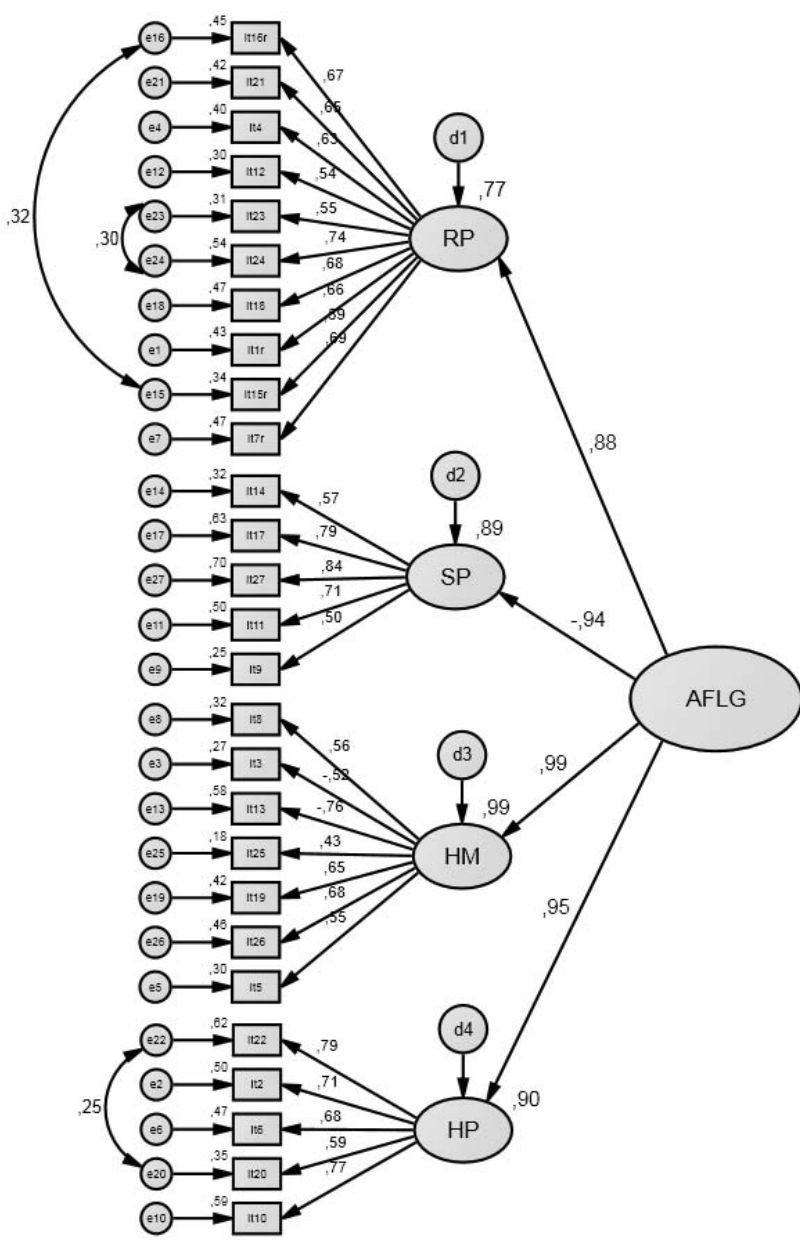

Figura 3. Modelo de segunda ordem da EMAFLG (Brasil).

Como se pode observar na Figura 3, os itens apresentam pesos fatoriais elevados e significativos no fator para o qual foram especificados. $\mathrm{O}$ mesmo se verifica no que diz respeito aos pesos da regressão dos fatores de primeira ordem no fator geral de segunda ordem. Finalmente, a consistência da escala total, medida pelo alfa de Cronbach estratificado (que contrariamente ao alfa de Cronbach não subestima a verdadeira consistência de escalas multifato- riais), apresentou um valor elevado $(0,87)$. Nesta medida, a medição do nível global de atitudes face a lésbicas e a gays apresentou elevada confiabilidade. Perante estes resultados, a utilização do escore global do instrumento surge como uma possibilidade no Brasil.

\section{Considerações Finais}

Descreveu-se neste artigo o processo de validação e adaptação transcultural de um instrumento que avalia quatro tipos de atitudes face a lésbicas e a gays. Num primeiro estudo, a validade de constructo da EMAFLG foi demonstrada nos seus três componentes (validade fatorial, validade convergente e validade discriminante), junto de uma amostra de estudantes universitários portugueses. Num segundo estudo, procurou-se demonstrar a legitimidade do uso do instrumento noutra cultura, utilizando para tal uma amostra de estudantes brasileiros. Como salientaram Avanci, Assis, Santos e Oliveira (2007, p. 403), "Embora muitos pesquisadores já estejam preocupados com estratégias de adaptação transcultural de instrumentos criados em uma cultura e transpostos para outra, ainda são escassos estudos que seguem uma metodologia mais refinada". Nesta medida, recorrendo a AFCMG provou-se, num segundo estudo, a invariância do instrumento numa amostra de estudantes universitários brasileiros.

Os resultados e conclusões da presente investigação devem ser lidos tendo em conta algumas limitações. Em primeiro lugar, uma vez que as propriedades psicométricas de um instrumento de medida dizem respeito a um determinado instrumento numa determinada amostra e não ao instrumento per se, recomenda-se para a utilização da EMAFLG a confirmação da sua estrutura fatorial na amostra em estudo, particularmente se não se tratar de uma amostra de jovens estudantes universitários. Em segundo lugar, dado que no Brasil os fatores do instrumento parecem refletir diversos aspetos de um mesmo traço, isto é, uma atitude geral face a lésbicas e a gays, novos estudos são necessários para confirmar se noutras amostras se verifica o mesmo fenómeno. Em terceiro lugar, a orientação sexual dos participantes não era conhecida. Contudo, uma vez que as pessoas não heterossexuais detêm, com maior probabilidade, atitudes menos estereotipadas e hostis relativamente aos seus congéneres, a presença de partici- 
pantes lésbicas e gays pode ter reduzido a amplitude das diferenças observadas nas atitudes mensuradas. Deve, no entanto, ser notado que esta limitação aumenta a probabilidade de ocorrência do erro de tipo-II, não invalidando os resultados. Finalmente, estudos futuros são necessários para a análise de outros tipos de validade do instrumento. Assim, sugere-se que se teste a validade concorrente da EMALFG recorrendo a outros instrumentos do mesmo tipo já construídos ou adaptados para a população portuguesa (por exemplo, A. Pereira et al., 2009b) ou brasileira (por exemplo, Cerqueira-Santos et al., 2007). A validade de constructo da EMAFLG pode ainda ser reforçada através de análises diferenciais em função de fatores que mostraram estar associados à homofobia, como, por exemplo, o gênero (Cerqueira-Santos et al., 2007; Gato et al., 2012; Kite \& Whitley, 1996), o contato interpessoal com lésbicas e gays (Bowen \& Bourgeois, 2001; Cerqueira-Santos et al., 2007; Gato et al., 2012; Herek \& Capitanio, 1996; Iraklis, 2010), a idade (Kelley, 2001), ou ainda o grau de religiosidade (Finlay \& Walther, 2003; Fisher, Derison, Polley, Cadman, \& Johnston, 1994).

Em síntese, a EMAFLG é um instrumento inovador na medida em que avalia simultaneamente diversos tipos de atitudes face a lésbicas e a gays e não se baseia exclusivamente em modelos pensados para pensar o preconceito racial/étnico. As estruturas fatoriais analisadas são válidas, o que possibilita o seu uso em investigações que necessitem de medir atitudes no domínio em estudo, em Portugal e no Brasil.

\section{Referências}

Almeida, L. M., \& Crillanovick, Q. (1999). A cidadania e os direitos humanos de gays, lésbicas e travestis no Brasil. In D. D. Oliveira, R. B. Lima, S. A. Santos, \& T. L. D. Tosta (Eds.), 50 anos depois: Relações raciais e grupos socialmente segregados (pp. 167-183). Goiânia, GO: Movimento Nacional de Direitos Humanos.

Anastasi, A., \& Urbina, S. (1997). Psychological testing ( $7^{\text {th }}$ ed.). New York: Prentice Hall.

Andersen, R., \& Fetner, T. (2008). Cohort differences in tolerance of homosexuality: Attitudinal change in Canada and the United States, 1981-2000. Public Opinion Quarterly, 72(2), 311-330.

Anjos, G. (2002). Homossexualidade, direitos humanos e cidadania. Sociologias, 4(7), 222-252.

Arbuckle, J. L. (2008). Amos 17 users' guide. Chicago, IL: Statistical Package for the Social Sciences.

Avanci, J. Q., Assis, S. G., Santos, N. C., \& Oliveira, R. V. C. (2007). Adaptação transcultural de Escala de Auto-estima para Adolescentes. Psicologia: Reflexão \& Crítica, 20(3), 397-405.

Bentler, P. M. (1990). Comparative fit indexes in structural models. Psychological Bulletin, 107, 238-246.

Bowen, A. M., \& Bourgeois, M. J. (2001). Attitudes toward lesbian, gay and bisexual college students: The contribution of pluralistic ignorance, dynamic social impact, and contact theories. Journal of American College Health, 50(2), 91-96.

Carneiro, N. S. (2009). Homossexualidades: Uma psicologia entre o ser, pertencer e participar. Porto, Portugal: Livraria de Psicologia e de Ciências da Educação.
Carneiro, N. S., \& Menezes, I. (2007). From an oppressed citizenship to affirmative identities: Lesbian and gay political participation in Portugal. Journal of Homosexuality, 53(3), 65-82.

Castro, M. G., Abramovay, M., \& Silva, L. B. (2004). Juventudes e sexualidades. Brasília, DF: Unesco.

Cerqueira-Santos, E., Winter, F. S., Salles, L. A., Longo, J. L., \& Teodoro, M. L. M. (2007). Contato interpessoal e crenças sobre homossexualidade: Desenvolvimento de uma escala. Interação em Psicologia, 11(2), 221-229.

Chen, F. F. (2007). Sensitivity of goodness of fit indexes to lack of measurement invariance. Structural Equation Modeling, 14(3), 464-504.

Cheung, G. W., \& Rensvold, R. B. (2002). Evaluating goodnessof-fit indexes for testing measurement invariance. Structural Equation Modeling, 9, 233-255.

Clarke, V., Ellis, S. J., Peel, E., \& Riggs, D. W. (2010). Lesbian, gay, bisexual, trans \& Queer psychology. Cambridge, MA: University Press.

Conselho Nacional de Combate à Discriminação. (2004). Brasil sem homofobia: Programa de combate à violência e à discriminação contra GLTB e promoção da cidadania homossexual. Brasília, DF: Ministério da Saúde.

Comissão Europeia. (2008). Special Eurobarometer 296. Discrimination in the European Union: Perceptions, experiences and attitudes, chapter. Retrieved May 10, 2010, from http:// ec.europa.eu/public_opinion/archives/ebs/ebs_296_sheet pt.pdf

Comissão Europeia. (2009). Discriminação na EU 2009. Retrieved May 10, 2010, from http://ec.europa.eu/public_opinion/ archives/ebs/ebs_317_fact_pt_pt1.pdf

Costa, C. G., Pereira, M., Oliveira, J. M., \& Nogueira, C. (2010). Imagens sociais de pessoas GLBT. In C. Nogueira \& J. M. Oliveira (Eds.), Estudo sobre a discriminação em função da orientação sexual e da identidade de género (pp. 93-147). Lisboa, Portugal: Comissão para a Cidadania e a Igualdade de Género.

Davidov, E., Schmidt, P., \& Schwartz, S. (2008). Bringing values back in: The adequacy of the European Social Survey to measure values in 20 countries. Public Opinion Quarterly, 72(3), 420-445.

Finlay, B., \& Walther, C. S. (2003). The relation of religious affiliation, service attendance, and other fators to homophobic attitudes among university students. Review of Religious Research, 44, 370-393.

Fisher, R. D., Derison, D., Polley, C. F., Cadman, J., \& Johnston, D. (1994). Religiousness, religious orientation, and attitudes towards gays and lesbians. Journal of Applied Social Psychology, 24, 614-630.

Gaertner, S. L., \& Dovidio, J. F. (Eds.). (2000). Reducing intergroup bias: The common in group identity model. Hove, UK: Psychology Press.

Gato, J., Carneiro, N. S., \& Fontaine, A. M. (2011). Contributo para uma revisão histórica e crítica do preconceito contra as pessoas não heterossexuais. Crítica e Sociedade: Revista de Cultura Política, 1(1), 139-167.

Gato, J., Fontaine, A. M., \& Carneiro, N. S. (2012). Escala Multidimensional de Atitudes Face a Lésbicas e a Gays: Construção e validação preliminar. Paidéia (Ribeirão Preto), 22(51), 11-20.

Haas, A. P., Eliason, M., Mays, V. M., Mathy, R. M., Cochran, S. D., D'Augelli, A. R., ...Clayton, P. J. (2011). Suicide and suicide risk in lesbian, gay, bisexual, and transgender populations: Review and recommendations. Journal of Homosexuality, 58(1), 10-51. 
Gato, J., Fontaine, A. M. \& Leme, V. B. R. (2014). Validação e Adaptação Transcultural da Escala Multidimensional de Atitudes Face a Lésbicas e a Gays.

Harkness, J. A., Van de Vijver, F. J. R., \& Mohler, P. P. (2003) Cross-cultural survey methods. New York: John Wiley.

Herek, G. M. (1988). Heterosexuals' attitudes toward lesbians and gay men: Correlates and gender differences. The Journal of Sex Research, 25(4), 451-477.

Herek, G. M. (1994). Assessing heterosexuals' attitudes toward lesbians and gay men. In B. Greene \& G. M. Herek (Eds.), Lesbian and gay psychology: Theory, research and clinical applications (pp. 206-228). Thousand Oaks, CA: Sage.

Herek, G. M. (2000). The psychology of sexual prejudice. Current Directions in Psychological Science, 9(1), 19-22.

Herek, G. M. (2007). Confronting sexual stigma and prejudice: Theory and practice. Journal of Social Issues, 63(4), 905-925.

Herek, G. M. (2009). Hate crimes and stigma-related experiences among sexual minority adults in the United States: Prevalence estimates from a national probability sample. Journal of Interpersonal Violence, 24, 54-74.

Herek, G. M., \& Capitanio, J. P. (1996). Some of my best friends: Intergroup contact, concealable stigma, and heterosexuals' attitudes toward gay men and lesbians. Personality and Social Psychology Bulletin, 22(4), 412-424.

Hudson, W. W., \& Ricketts, W. A. (1980). A strategy for the measurement of homophobia. Journal of Homosexuality, 5(4), 357-372.

Hui, C. H., \& Triandis, H. C. (1985). Measurements in crosscultural psychology. Journal of Cross-Cultural Psychology, 16(2), 131-152.

Iraklis, G. (2010). Predictors of Greek students' attitudes towards lesbians and gay men. Psychology \& Sexuality, 1(2), 170-179.

Kelley, J. (2001). Attitudes towards homosexuality in 29 nations. Australian Social Monitor, 4(1), 15-21.

Kite, M. E., \& Deaux, K. (1986). Attitudes toward homosexuality: Assessment and behavioral consequences. Basic and Applied Social Psychology, 7(2), 137-162.

Kite, M. E., \& Deaux, K. (1987). Gender belief systems: Homosexuality and implicit inversion theory. Psychology of Women Quarterly, 11, 83-96.

Kite, M. E., \& Whitley, B. E. (1996). Sex differences in attitudes toward homosexual persons, behaviors, and civil rights: A meta-analysis. Personality and Social Psychology Bulletin, 22(4), 336-353.

Kite, M. E., \& Whitley, B. E. (1998). Do heterosexual women and men differ in their attitudes toward homosexuality? A conceptual and methodological analysis. In G. M. Herek (Ed.), Psychological perspectives on lesbian and gay issues. Stigma and sexual orientation, understanding prejudice against lesbians, gay men, and bisexuals: Vol. 4 (pp. 39-61). Thousand Oaks, CA: Sage.

Kitzinger, C. (1987). The social construction of lesbianism. Beverly Hills, CA: Sage.

Kline, R. B. (2011). Principles and practice of structural equation modeling ( $3^{\text {rd }}$ ed.). New York: Guilford Press.

Lacerda, M., Pereira, C., \& Camino, L. (2002). Um estudo sobre as formas de preconceito contra homossexuais na perspectiva das representações sociais. Psicologia: Reflexão e Crítica, 15(1), 165-178.

Marôco, J. (2010). Análise de equações estruturais: Fundamentos teóricos, software \& aplicações. Pêro Pinheiro, Portugal: ReportNumber.

Marshal, M. P., Dietz, L. J., Friedman, M. S., Stall, R., Smith, H. A., McGinley, J., ...Brent, D. A. (2011). Suicidality and depression disparities between sexual minority and heterosexual youth: A meta-analytic review. Journal of Adolescent Health, 49(2), 115-123.
McConahay, J. B. (1986). Modern racism, ambivalence and the modern racism scale. In J. F. Dovidio \& S. L. Gaertner (Eds.), Prejudice, discrimination and racism (pp. 91-124). New York: Academic Press.

Meertens, R., \& Pettigrew, T. F. (1999). Será o racismo subtil mesmo racismo? In J. Vala, (Ed.). Novos racismos: Perspectivas comparadas (pp. 11-29). Oeiras, Portugal: Celta.

Morin, S. F. (1977). Heterosexual bias in psychological research on lesbianism and male homosexuality. American Psychologist, 32, 117-128.

Morrison, T. G., Kenny, P., \& Harrington, A. (2005). Modern prejudice toward gay men and lesbian women: Assessing the viability of a measure of modern homonegative attitudes within an Irish context. Genetic, Social, and General Psychology Monographs, 131(3), 219-250.

Nogueira, C., \& Oliveira, J. M. (2010). Um olhar da psicologia feminista crítica sobre os direitos humanos de pessoas GLBT. In C. Nogueira \& J. M. Oliveira (Eds.), Estudo sobre a discriminação em função da orientação sexual e da identidade de género (pp. 9-17). Lisboa, Portugal: Comissão para a Cidadania e a Igualdade de Género.

Oliveira, J. M., Pereira, M., Costa, C. G., \& Nogueira, C. (2010). Pessoas LGBT - Identidades e discriminações. In C. Nogueira \& J. M. Oliveira (Eds.), Estudo sobre a discriminação em função da orientação sexual e da identidade de género (pp. 149-210). Lisboa, Portugal: Comissão para a Cidadania e Igualdade de Género.

Park, J. (2001). Development of the Heterosexism Scale (Doctoral dissertation, Pennsylvania State University, State College, PA, EUA). Retrieved December 15, 2008, from http://search. proquest.com/pqdtft/docview/304719844/fulltextPDF/13374 B625722BEE9A4E/1?accountid=43623

Pereira, A., Monteiro, M. B., \& Camino, L. (2009a). Social norms and prejudice against homosexuals. The Spanish Journal of Psychology, 12(2), 576-584.

Pereira, A., Monteiro, M. B., \& Camino, L. (2009b). Estudo da validação das escalas de crenças sobre a natureza da homossexualidade e de preconceito contra homossexuais. Laboratório de Psicologia, 7(1), 21-32.

Pereira, C. R., Torres, A. R. R., Pereira, A., \& Campos, L. (2011). Preconceito contra homossexuais e representações sociais da homossexualidade em seminaristas católicos e evangélicos. Psicologia: Teoria e Pesquisa, 27(1), 73-82.

Pettigrew, T., \& Meertens, R. (1995). Subtle and blatant prejudice in Western Europe. European Journal of Personality and Social Psychology, 75, 811-832.

Quiles del Castillo, M. N., Betancor Rodríguez, V., Rodríguez Torres, R., Rodríguez Pérez, A., \& Coello Martel, E. (2003). La medida de la homofobia manifiesta y sutil. Psicothema, 15(2), 197-204.

Raja, S., \& Stokes, J. P. (1998). Assessing attitudes toward lesbians and gay men: The Modern Homophobia Scale. Journal of Gay, Lesbian, and Bisexual Identity, 3(2), 113-134.

Schweizer, K. (2010). Some guidelines concerning the modelling of traits and abilities in test construction. European Journal of Psychological Assessment, 26(1), 1-2.

Vale de Almeida, M. (2010). O contexto LGBT em Portugal. In C. Nogueira \& J. M. Oliveira (Eds.), Estudo sobre a discriminação em função da orientação sexual e da identidade de género (pp. 45-92). Lisboa, Portugal: Comissão para a Cidadania e a Igualdade de Género.

Vandenberg, R. J., \& Lance, C. E. (2000). A review and synthesis of the measurement invariance methods and procedures. Organizational Research Methods, 3, 4-69. 
Venturi, G. (2009). Pesquisa - Intolerância à diversidade sexual. Recuperado em 10 maio, 2010 de http://www.fpanramo.org. br/o-que-fazemos/pesquisas-de-opiniao-publica/pesquisas-realizadas/apresentacao-4

Weinberg, G. (1972). Society and the healthy homosexual. New York: St. Martin's Press.

World Values Survey (1997). [Heterosexuals' attitudes toward gay men and lesbians: 1995 - 1998]. Retrieved July 17, 2009, from http://www.wvsevsdb.com

World Values Survey (1999). [Heterosexuals' attitudes toward gay men and lesbians: 1999-2004]. Retrieved July 17, 2009, from http://www.wvsevsdb.com

Wright, L. W., Adams, H. E., \& Bernat, J. (1999). Development and validation of the Homophobia Scale. Journal of Psychopathology and Behavioral Assessment, 21(4), 337-347. 
Gato, J., Fontaine, A. M. \& Leme, V. B. R. (2014). Validação e Adaptação Transcultural da Escala Multidimensional de Atitudes Face a Lésbicas e a Gays.

\section{Anexo}

\section{Versões Portuguesa e Brasileira (itens dentro de parênteses) da Escala Multidimensional de Atitudes Face a Lésbicas e a Gays}

1. Para mim é igual se os meus amigos são heterossexuais ou homossexuais.

2. A homossexualidade é uma perturbação psicológica.

3. Acredito que os pais e as mães homossexuais são tão competentes como os pais heterossexuais.

4. Os gays e as lésbicas enervam-me. (Os gays e as lésbicas irritam-me.)

5. A legalização do casamento entre pessoas do mesmo sexo irá abalar os princípios fundamentais da sociedade.

7. Se fosse pai ou mãe, poderia aceitar que o meu filho ou a minha filha fosse homossexual. (Se fosse pai ou mãe, aceitaria se o meu filho ou a minha filha fosse homossexual.)

8. Ser criado num lar homossexual é bastante diferente de ser criado num lar heterossexual.

9. Um programa escolar de educação sexual deveria referir-se a todas as orientações sexuais.

10. A crescente aceitação da homossexualidade na nossa sociedade está a contribuir para a deterioração dos valores morais. (A crescente aceitação da homossexualidade na nossa sociedade está contribuindo para a deterioração dos valores morais.)

11. As organizações que promovem os direitos dos homossexuais são necessárias.

12. Hesitaria em apoiar pessoas homossexuais com medo de ser confundido/a com elas.

13. Os casais do mesmo sexo deveriam, tal como os casais heterossexuais, poder adotar crianças.

14. As pessoas que assumem a sua homossexualidade devem ser admiradas pela sua coragem.

15. Não me importo que uma empresa contrate uma figura pública abertamente homossexual para fazer publicidade aos seus produtos.

16. Não me importaria de trabalhar com uma pessoa que fosse homossexual.

17. As lésbicas e os gays ainda precisam de lutar por direitos iguais.

18. Sentir-me-ia desconfortável se soubesse que o professor ou a professora de um filho meu ou de uma filha minha era homossexual. (Sentiria-me desconfortável se soubesse que o professor ou a professora de um filho meu ou de uma filha minha era homossexual.)

19. Celebrações como o "dia do orgulho gay" são ridículas porque assumem que a orientação sexual deve constituir um motivo de orgulho.

20. Se realmente quisessem, as lésbicas e os gays poderiam ser heterossexuais.

21. Sentir-me-ia pouco à vontade se descobrisse que o meu médico ou a minha médica não era heterossexual. (Sentiria-me pouco à vontade se descobrisse que o meu médico ou a minha médica não era heterossexual.)

22. As lésbicas e os gays deveriam submeter-se a terapia para mudar a sua orientação sexual.

23. Sinto que não se pode confiar numa pessoa que é homossexual. RP

24. Não votaria num/a candidato/a homossexual nas eleições. RP

25. Quando ouço falar numa relação amorosa, parto do princípio que são duas pessoas do sexo oposto. HM

26. Os gays e as lésbicas deveriam parar de impingir o seu estilo de vida aos outros. HM

27. Vejo o movimento gay como algo de positivo. SP

Nota. $\mathrm{RP}=$ Rejeição da proximidade; HP = Homopatologização; HM = Heterossexismo moderno; $\mathrm{SP}=\mathrm{Suporte}$. 